\title{
Development of software for easy prediction of process parameters in air bending with local heating
}

\author{
J.A. Canteli, J.L. Cantero and M.H. Miguélez* \\ Mechanical Engineering Department, \\ University Carlos III of Madrid, \\ Avd. Universidad 30, 28911 Leganés, Madrid, Spain \\ E-mail: jcanteli@ing.uc3m.es \\ E-mail: jcantero@ing.uc3m.es \\ E-mail: mhmiguel@ing.uc3m.es \\ ${ }^{*}$ Corresponding author
}

\begin{abstract}
This paper presents a new software tool for sheet metal forming, based on an analytical model of the process. The advantages of this kind of tool, compared with numerical models based on finite element codes, are described. The analysis is focused on sheet metal bending at high temperature that is a promising method for metal forming, improving sheet formability and machines range of use.
\end{abstract}

Keywords: analytical model; finite element analysis; sheet metal forming.

Biographical notes: J.A. Canteli has been an Industrial Engineer since 1969 and has worked as a Senior Engineer for more than 30 years for several manufacturers in the aerospace, nuclear and automotive sectors, being Head of the Production Department for more than 20 years. He pursued his doctorate on the modelling of sheet metal forming at high temperatures. Currently he is a fulltime professor at University Carlos III, focusing his work on the modelling and control of manufacturing processes.

J.L. Cantero has been an Industrial Engineer since 1998 and pursued his doctorate in industrial engineering, dealing with instrumentation and control of manufacturing processes (2001). He is a fulltime Assistant Professor at University Carlos III, working on instrumentation, control of processes, and machinability.

M.H. Miguélez has been an Aeronautical Engineer since 1994 and pursued his doctorate in industrial engineering (1998) on the characterisation of advanced materials under dynamic loading. Currently he is a Professor at University Carlos III, working on advanced materials, improvement of manufacturing processes and modelling. 


\section{Introduction}

Producing better quality, reducing the manufacturing cost and delivering the product quickly have become three major targets for the manufacturing industry. To achieve these, manufacturing companies have to adopt new technology based strategies (Liu et al., 2004). Hydromechanical forming is one of these new technologies which satisfy the industrial requirements. A technological advantage of the hydromechanical forming compared to conventional forming technologies, is to achieve a more uniform thickness distribution over the component, due to the introduction of hydrostatic pressure. This results in greater drawing ratios and more favourable distribution of residual stresses, with an expected reduction in springback after the forming process. The hydroformed component also satisfies improved geometrical accuracy and surface finish requirements so that it can be used without any further finishing operations (Kima et al., 2004). Flexible forming using plasma arc is another method of sheet metal forming, recently developed. It makes the forming by means of thermal stress and thermal strain without mould and die and is recognised as a promising forming method in manufacturing new products (Xua et al., 2005). Also conventional tools are modified in order to obtain new forming processes, as in the case of multipoint forming. The fundamental idea of multipoint forming for sheet metal is to replace the conventional solid dies in stamping by a pair of opposed matrices of punches. The movement of each punch is controlled independently, and so this is a flexible processing technique (Cai and $\mathrm{Li}, 2005$ ). One of the important advantages of this method is that the forming path of metal sheet can be adjusted freely and a sheet product can be manufactured along an optimum forming path with least risk of forming failure. Another technique based on the use of no conventional tools is incremental sheet metal forming (Kopac and Kampus, 2005). This is a promising process providing a short and inexpensive way of forming products having a relatively simple but interesting shape. The process is controlled by a CNC milling machinetool, together with a CAD/CAM Master Cam system and a smooth forming tool.

High tooling costs and low numbers of parts produced are typical characteristics of the manufacturing process of sheet metal parts for vehicle components (Hsu et al., 2002; Walczyk et al., 1998). The development of accurate models capable of predicting parameters process combining time and cost reduction could help to achieve design objectives, thus avoiding the practice of linking a variety of models (Anokye-Siribor and Singh, 2000; de Vin et al., 1996). Many authors have developed analytical and numerical models for sheet metal forming processes (Elkins and Sturges, 1999; Forcellese et al., 1998; Lei et al., 2001, 2002). Numerical models based on finite element simulations are an efficient tool for supporting sheet metal forming processes. One of the most important topics related to modelling of sheet metal forming is the implementation of new constitutive equations capable of accurately predicting material behaviour. As an example, the constitutive model developed by Iwamoto and Tsuta (2000), was implemented in the user's material subroutine of the finite element code Abaqus/Explicit, as described in Serri (2005). In this work the transformation induced plasticity resulting from the martensitic transformation observed in low temperature austenitic steels, was studied. Numerical simulations were performed with the aim of analysing the influence of the different parameters of the constitutive laws on the predicted formability of these materials. Another original phenomenological thermoviscousplastic model that encompasses strain hardening, strain rate and temperature sensitivity is reported in 
Rusinek et al. (2005). The model is based, to some extent, on the concept of physical modelling proposed in Klepaczko (1975) and by other authors (Kocks, 1976; Meyers et al., 2002; Gibbs, 1969). In this work, the original constitutive equation is implemented in a FEM (finite element method) code (Abaqus/Explicit). A comparison is also made between the proposed constitutive relation, called RK, and other formulations, such as Johnson-Cook or Cowper-Symonds, implemented into finite element codes. With the combination of the original thermoviscoplastic model and a new integration scheme that includes strain hardening, strain rate sensitivity and temperature effects, it is possible to simulate and study a variety of processes of sheet metal forming. On the same lines, a new model which includes more classical phenomenological models, in order to take into account either the isotropic or the kinematic hardening or both, is presented in Bouvier et al. (2005).

It is not only the constitutive equation that should be improved to simulate forming processes. It is wellknown that the metallic material is subjected to large irreversible deformation in a sheet forming process such as stamping or deepdrawing, leading to high strain localisation zones and then internal or superficial microdefects (ductile damage). An efficient pseudoinverse approach, with a deformation damage model to predict the damage evolution in the sheet forming process is described in Guo et al. (2004). Other works dealing with damage evolution in sheet metal forming are reported in Lademo et al. (2004) and Chan et al. (2004).

An interesting work on the optimisation of the drawin of an automotive sheet metal part has been reported in Jansson et al. (2005). The optimisation was carried out using response surface methodology and space mapping technique. In this study it was proven that space mapping is a very effective and accurate method to use when calibrating the drawin of a sheet metal process. In order to establish draw bead geometry from the draw bead restraining force, a 2D model was used. The draw bead geometry found showed good agreement with the physical draw bead geometry.

Reviewed articles are examples of the numerous research works dealing with sheet metal forming. Models reviewed present good accuracy to simulate experimental tests. However, the complex mathematical formulation of the described models does not facilitate the widespread use of these research works in industry, especially in the case of smaller suppliers.

On the other hand, in recent years the vehicle manufacture industry has paid much attention to weight reduction technologies without decrease in the vehicle crash safety. The key to understand the motivation for the use of advanced materials with improved strength in a vehicle, is the fact that the replacement materials, implies a mass reduction that is a proven method for obtaining improved fuel economy (Sutherland et al., 2004). As an approximation, a $10 \%$ reduction in mass produces a $5 \%$ improvement in fuel economy. To achieve higher vehicle energy efficiencies, lighter high strength materials should be used, with the disadvantage of their reduced formability (Nishino et al., 2003; Gomes et al., 2005; Chien et al., 2004). Since designers/manufacturers have less experience with these materials, research is needed to support their use in vehicle applications.

Although most sheet metal forming processes are usually carried out at room temperature, forming at elevated temperature (Novotny and Geiger, 2003; Lang et al., 2004) could solve, in part, associated problems. High temperature in the work piece results in material softening, the formability being increased and the maximum process force decreased. This is an advantage when improved mechanical properties of 
the work piece material are required, as in the case of automotive components. If the maximum force is decreased, it is possible to have more flexibility when a machine is used, because it would be possible to manufacture work pieces with increased thickness, for example (Canteli, 2003). This is another advantage when small batch sizes in sheet metal part manufacturing are needed.

The main goals of this paper could be summarised as two objectives. First, a new technique for sheet metal forming at high temperature is presented. This may be a solution for several problems involved in high strength materials forming and for the requirement of flexibility for manufacturing processes. Secondly, modelling, both numerical and analytical, of this process is analysed. Based in these models new software for direct implementation of described process in industry is presented. This computer tool may solve the problem of implementation of accurate, but complex models in industry.

In this paper, attention is focused on air bending at local elevated temperatures, along the bend length. Bending at room temperature is one of the most usual forming operations. Aircraft, trucks, industrial and agricultural vehicles are examples of vehicles with different components based on this technique. In air bending a sheet is bent on a press brake with the use of a punch and a die. The punch is lowered to a precalculated position, not completely; so it is possible to obtain different bend angles with the same set of tools. However the complexity of the process should not be underestimated (Vin, 2001). Process models based on realistic assumptions should be established in order to predict punch penetration and bend angle, according to actual process conditions.

Local heating of the sheet along the bend length previously to punch-sheet interaction, would provide some advantages, as was explained initially. High temperature in a narrow area around bend length, involves less maximum force, reduced springback and improved bendability. Avoiding complete heating of the sheet, oxidation over an extended surface is prevented, energy cost is lower and furnace dimensions are smaller than in the case of introduction of the sheet into the furnace (Canteli, 2003).

A numerical model of the process based on FEM analysis is presented. Applications of FEM to sheet metal forming analysis, with the aim to better understand the forming processes, are developed in big companies and research departments during concurrent design and manufacture processes (Woznica and Klepaczko, 2003). However smaller suppliers do not have the same human and technical resources. The implementation of new technologies (like high temperature sheet metal processing) calls for computer tools, based on numerical and analytical models, predicting the most important parameters in the process.

In this work a thermomechanical model for air bending with local heating is summarised. This model was validated with experimental tests and it is able to predict process parameters accurately. More details about this model can be found in previous works of the authors (Canteli et al., 2004). Based in this analytical model, friendly software, easy to implement in production departments, was developed, being another example of a tool developed in a research department with direct application in automotive industrial activities (Bouchard and Aoussat, 2003a; Bouchard and Aoussat, 2003b).

This paper is structured in seven sections, this introduction being the first one. The second section summarises the methodology followed to develop the computer tool presented in this paper. Heating devices, press brakes and tests developed to validate the models, are described in the third section. The fourth and fifth sections summarise, 
respectively, the numerical and analytical analysis of bending at high temperature. The sixth section presents a new computer tool based on the analytical model, previously validated. A brief comparison between the FEM model, the analytical model and the developed tool is presented, showing the main advantages of latest. The last section summarises the conclusions obtained from this research work.

\section{Methodology}

As was shown in the introduction, the main objective of this work is the development of a computer tool, able to predict process parameters in air bending at high temperature. This software should be based in analytical models, so it is needed to develop theoretical studies to predict temperature distribution and bending parameters, once the heating parameters and desired work piece geometry are stated.

Both thermal and mechanical problems are modelled. As is well known, when a model is formulated, several hypotheses are assumed, in order to simplify the problem. At the beginning of this work, both the thermal and mechanical models were compared with the numerical analysis of the problem. From this comparison new hypotheses in the analytical model were validated and the estimation of calculus time with a FEM code was obtained. As commercial FEM codes are computer tools that usually support process design in manufacturing, it is necessary to compare them with the new computer tool to know the advantages of the latest.

On the other hand, experimental work is always associated with modelling (numerical or analytical) because model validation is needed. Comparison between calculated and measured parameters allows for calculating the errors of the model predictions. Experimental work was carried out in the same ranges as the model parameters. Sheet geometry, temperatures, punch and die geometry are stated in the ranges that are usual in sheet bending.

Modelling should be done taking into account experimental devices that should be modelled. As an example, thermal distribution may be different if a heating device with two cylindrical resistances is designed (as is done in this work) or an alternative method is used (laser, for example).

The research work presented in this paper is summarised in the flowchart in Figure 1, showing the main techniques involved: analytical, numerical and experimental. The final step of the work is the software for prediction of process parameters when bending at high temperature is required.

\section{Experimental work}

\subsection{Material characterisation}

It has been shown that local heating improves the formability of work piece, because of material softening due to high temperature. First of all, it is needed to know the mechanical behaviour of the material involved in the experimental work.

Validation of both numerical and analytical models was carried out with stainless steel AISI 304. Temperature ( $T$ ) dependence of the constitutive equation parameters was established from experimental work. A large number of tests were carried out in order to 
obtain stress-strain curve parameters of this material, from room temperature to temperatures up to $770^{\circ} \mathrm{C}$. From these tests, constitutive equation parameters $E(T), \sigma_{0 e}(T)$, $K_{e}(T)$, (that are shown in Figure 2) were obtained as a function of temperature.

Figure 1 Flowchart of the research work presented in the paper

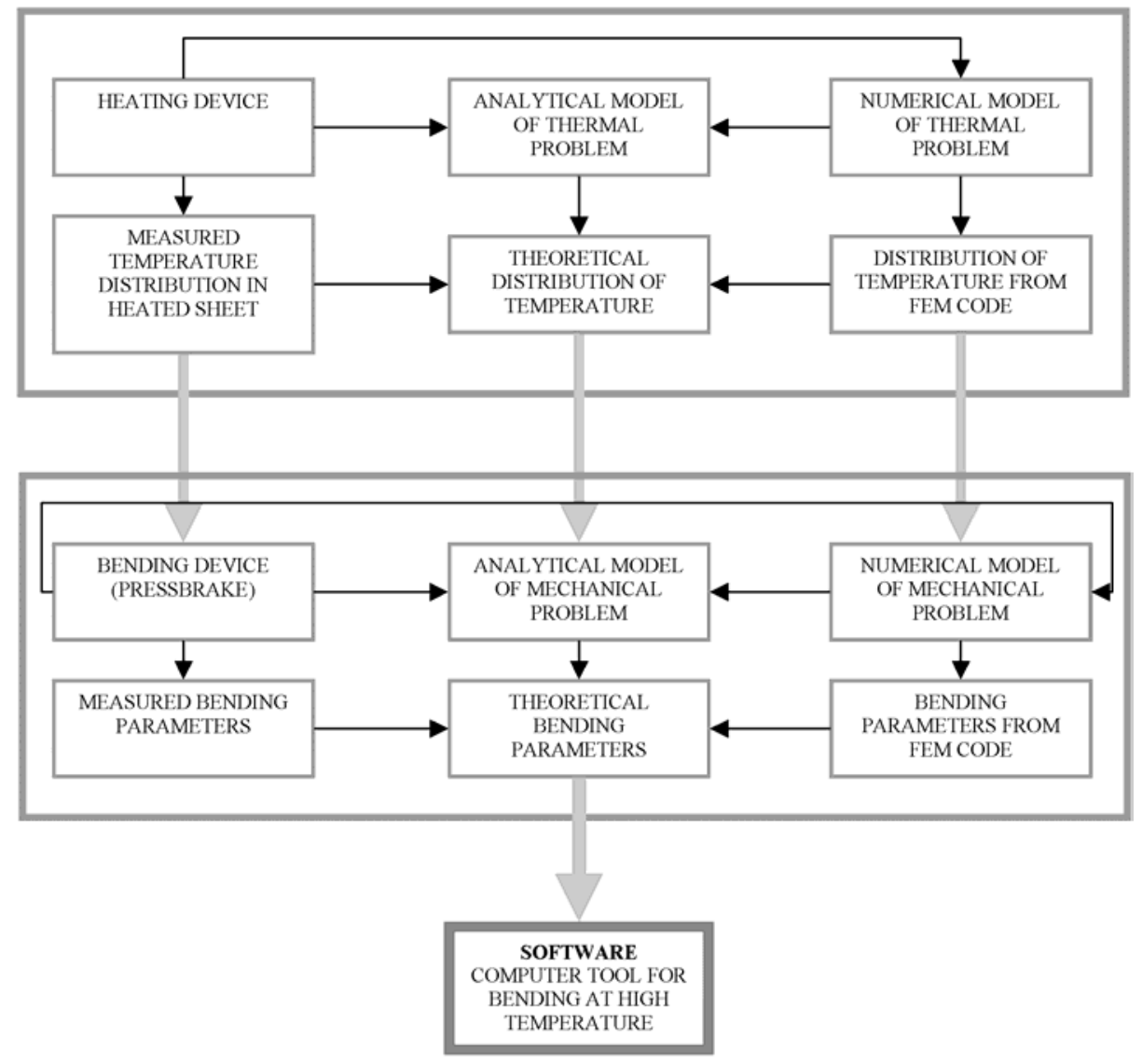

Figure 2 Parameters of constitutive equation of material sheet (AISI 304)

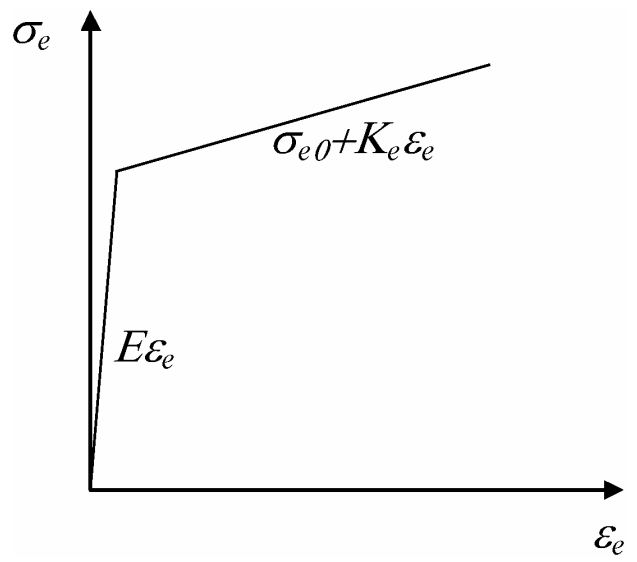


Mechanical behaviour of AISI 304 at high temperature is represented by three coefficients (temperature dependent) that multiply corresponding to the parameter value $\left(E, \sigma_{0 e}, K_{e}\right)$ at room temperature. Dependence of these coefficients on temperature is represented in Figure 3. Curves were adjusted by fifth and fourth order polynomials in $T$.

Figure 3 Coefficients of parameters of the constitutive equation vs. temperature

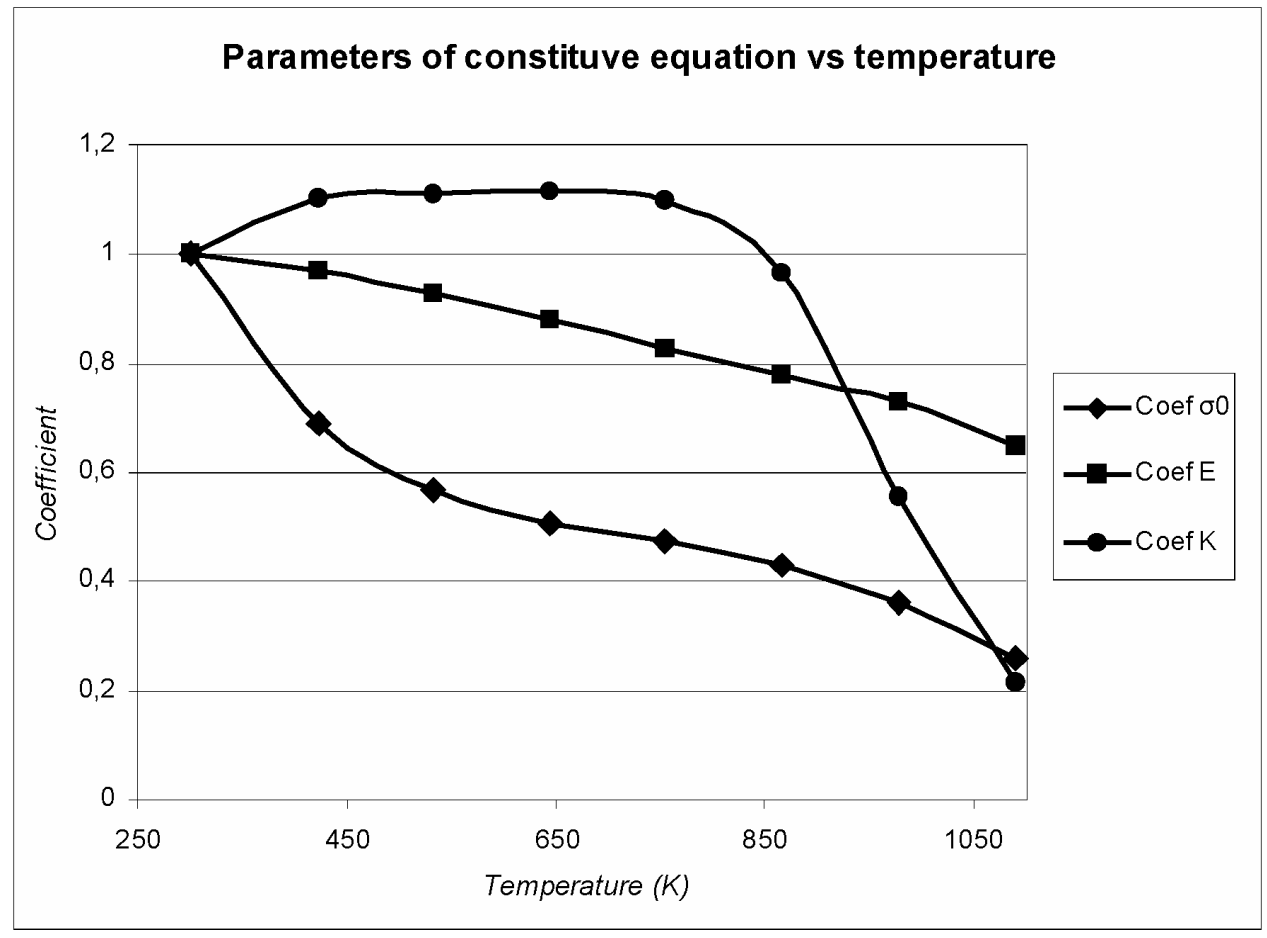

\subsection{Heating device}

The design of the heating device in this work was developed with the objective of using cheap and 'easy to implement in industry' technologies, to generate local heating in the sheet. The heating device designed and constructed here is only one possibility; different devices may be developed based in other techniques.

The heating device was designed and constructed to heat the sheet in a narrow area along bend length. It is clear that local heating presents advantages when it is compared to complete introduction of the sheet into a furnace at high temperature: the ease of handling hot sheets, smaller and less expensive equipments, local instead extended oxidation and energy saving, mainly.

In order to achieve the described objectives, the heating device was based on two standard electrical resistances (cylindrical shape, radius $6.3 \mathrm{~mm}$, length $400 \mathrm{~mm}$, power range from $900 \mathrm{~W} / \mathrm{m}$ to $2000 \mathrm{~W} / \mathrm{m}$ ), mounted on a test set as is shown in Figure 4. This configuration was modelled analytically and with FEM code. 
Figure 4 Sheet positioned on heating device before bending

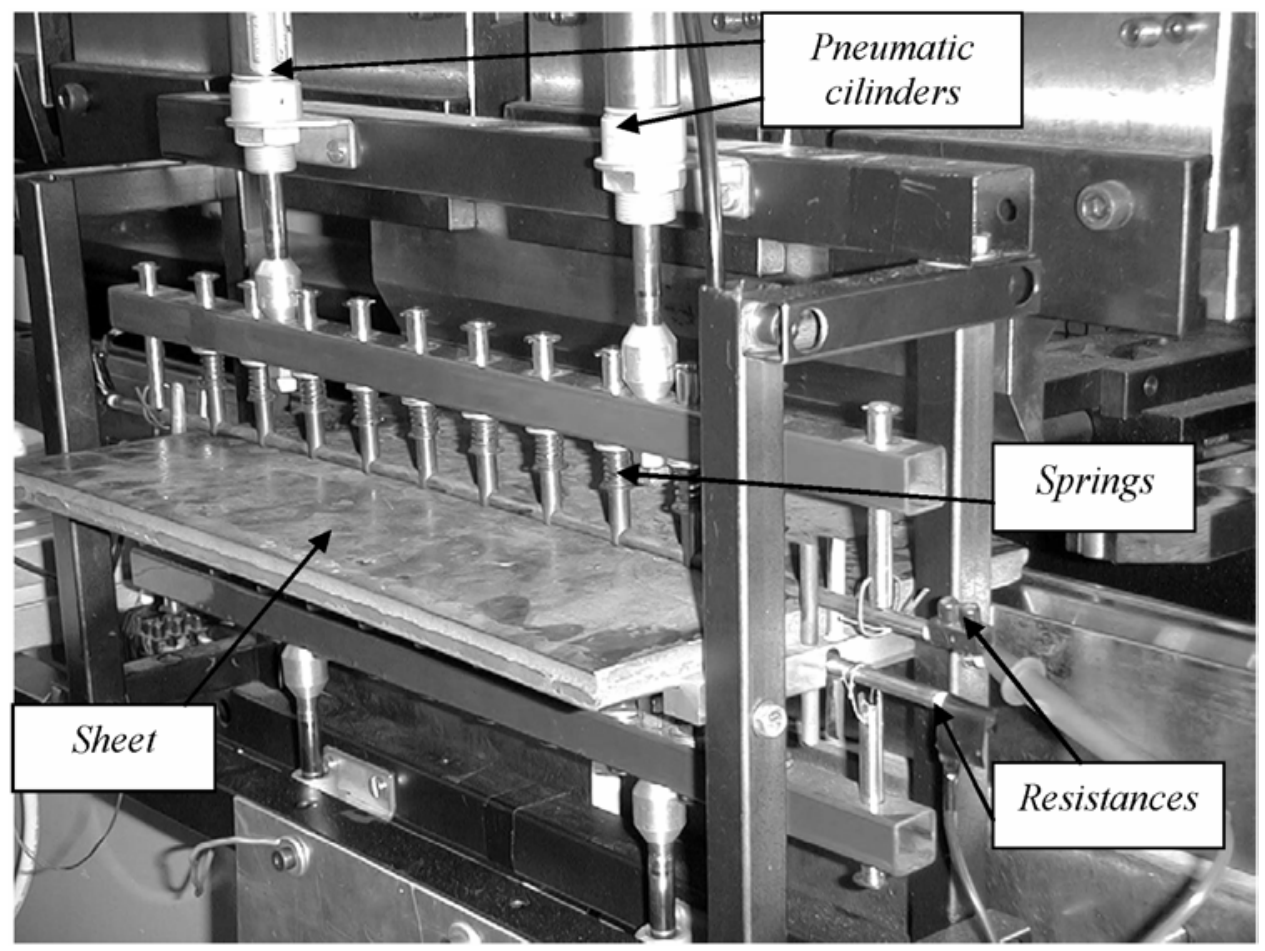

Once the resistances were heated up to a desired temperature, the sheet was located between both resistances and a contact force was applied (the contact force ranged from $375 \mathrm{~N} / \mathrm{m}$ to $750 \mathrm{~N} / \mathrm{m}$ ). The axes of resistances and the line that was going to be bent (after heating) were in the same plane.

After a heating time long enough to ensure permanent conditions in the sheet (20 minutes in the case of the thickest sheets), it was positioned in the press brake to carry out bending tests. The experimental set up was designed to allow quick positioning of the sheet in the press brake, avoiding temperature decrease.

As the temperature should be measured during thermal tests, the sheet was equipped with thermocouples. Validation of temperature distribution was carried out in thickest specimens $(6 \mathrm{~mm})$ because the installation of thermocouples required this thickness.

Thermal tests indicated temperature distribution in the sheet, once the thermal parameters (resistance power before and after contact, heating time and contact force between resistance and sheet) were fixed. Maximum temperatures up to $770^{\circ} \mathrm{C}$ along the bend length (corresponding to maximum contact forces and power resistances) were obtained. Comparison between measured and calculated temperatures allows for errors in theoretical predictions.

As it was not possible to bend the sheet equipped with thermocouples, bending tests were carried out with sheets that were not instrumented, heated with exactly the same parameters. Figure 4 is a photograph of the equipment during the heating phase of a sheet without thermocouples, prior to bending phase. 


\subsection{Bending device}

The selected machine for bending tests was a conventional hydraulic press brake LOIRE-SAFE with NC (numerical control) CYBELEC, its maximum bend length being $3050 \mathrm{~mm}$ and maximum nominal force being $900 \mathrm{KN}$.

This machine controlled the punch displacement and speed during bend tests. Punch position was also measured with a displacement transducer and compared with the internal displacement control of the machine. The signal from displacement transducer was distorted because of noise; however, the mean value of the displacement signal coincided reasonably with the signal obtained from the machine displacement controller. The punch displacement was finally obtained from internal control of the machine, during tests.

Standard tools were substituted by specially designed and constructed tools that allowed ranging of geometric parameters (punch radius, die aperture) and sheet geometry at desired intervals. Sheet thickness ranged from $2 \mathrm{~mm}$ to $6 \mathrm{~mm}$, punch radius ranged from $1 \mathrm{~mm}$ to $4 \mathrm{~mm}$ and die aperture from $6 \mathrm{~mm}$ to $12 \mathrm{~mm}$ thickness. The bend length of the sheet was enough to ensure plane strain conditions in the sheet.

A load cell was installed as a support of constructed dies. As the process is symmetrical, one half of the bending force is measured as is shown in Figure 5.

Figure 5 Load cell installed in modified die to measure bending force

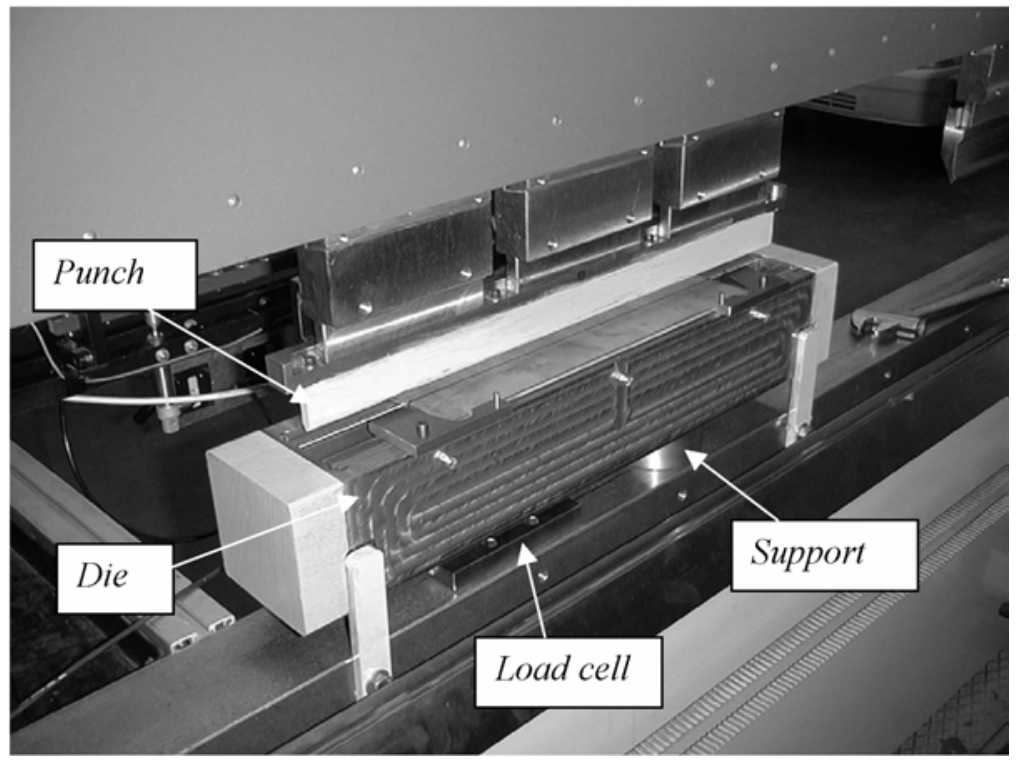

The hydraulic system of press brake was instrumented with a pressure sensor, obtaining another measure of bending force. Results obtained from both systems were coincident.

The bending angle was measured at the maximum displacement of the punch and after unloading.

The process parameters measured to compare with model results were bending force and bending angle before and after springback. The press brake and complete acquisition system is shown in Figure 6. 
Figure 6 Complete experimental set up with acquisition system

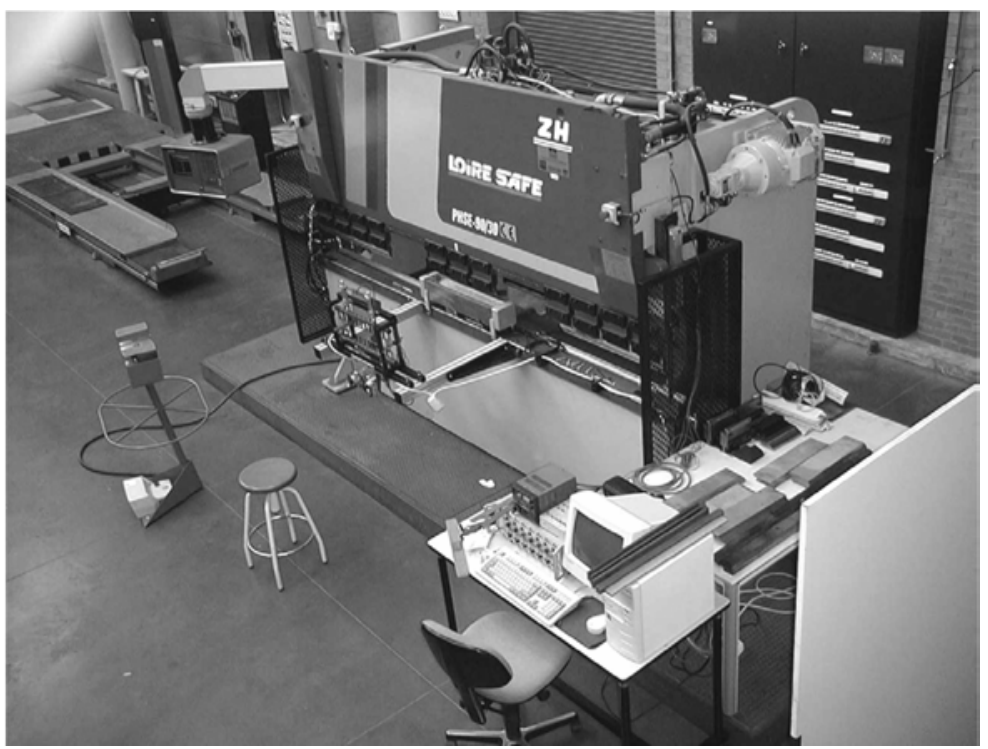

\section{$4 \quad$ FEM analysis}

\subsection{Temperature distribution}

Experimental set up, designed and fabricated in order to obtain an equipment easy to implement in the manufacture industry, determines the heating parameters. As was explained, the projected heating device consists of two electrical resistances located in a vertical plane containing the bend line, under and over the sheet along the bend length. The heating parameters are: time of heating $t$, resistance power $P$, contact force between resistance and sheet $a$, and resistance radius $R$.

Firstly, FEM analysis of the thermal problem was performed in a commercial code (ANSYS). In the model, the sheet is discretised in elements $\Delta x$ wide, $1 \mathrm{~m}$ long, and $e$ thick. The numerical model showed.

- Temperature is constant in the plane YZ, so only variation of temperature in the $X$ direction is considered. The $\mathrm{Z}$ axis is parallel to bend length, the plane $\mathrm{XZ}$ is coincident with the middle surface of the undeformed sheet, and the $\mathrm{Y}$ axis completes the reference system.

- The temperature is nonlinear with the $\mathrm{X}$ coordinate, so the temperature gradient in this direction is not constant. However, thermal induced stresses are not significant, because temperature nonlinearity with $\mathrm{X}$ is not very pronounced.

- Heating time to permanent conditions is less than twenty minutes for the parameter ranges studied in this work.

- Temperature was calculated and measured at different points of the sheet, in five values of time. When heating parameters ranged across the described intervals, the relative error in temperature distribution was always less than $5 \%$. 
Figure 7 shows temperature distribution in a sheet with thickness $6 \mathrm{~mm}$. Temperature up to $957 \mathrm{~K}$ was predicted along bend length

Figure 7 Calculated temperature distribution

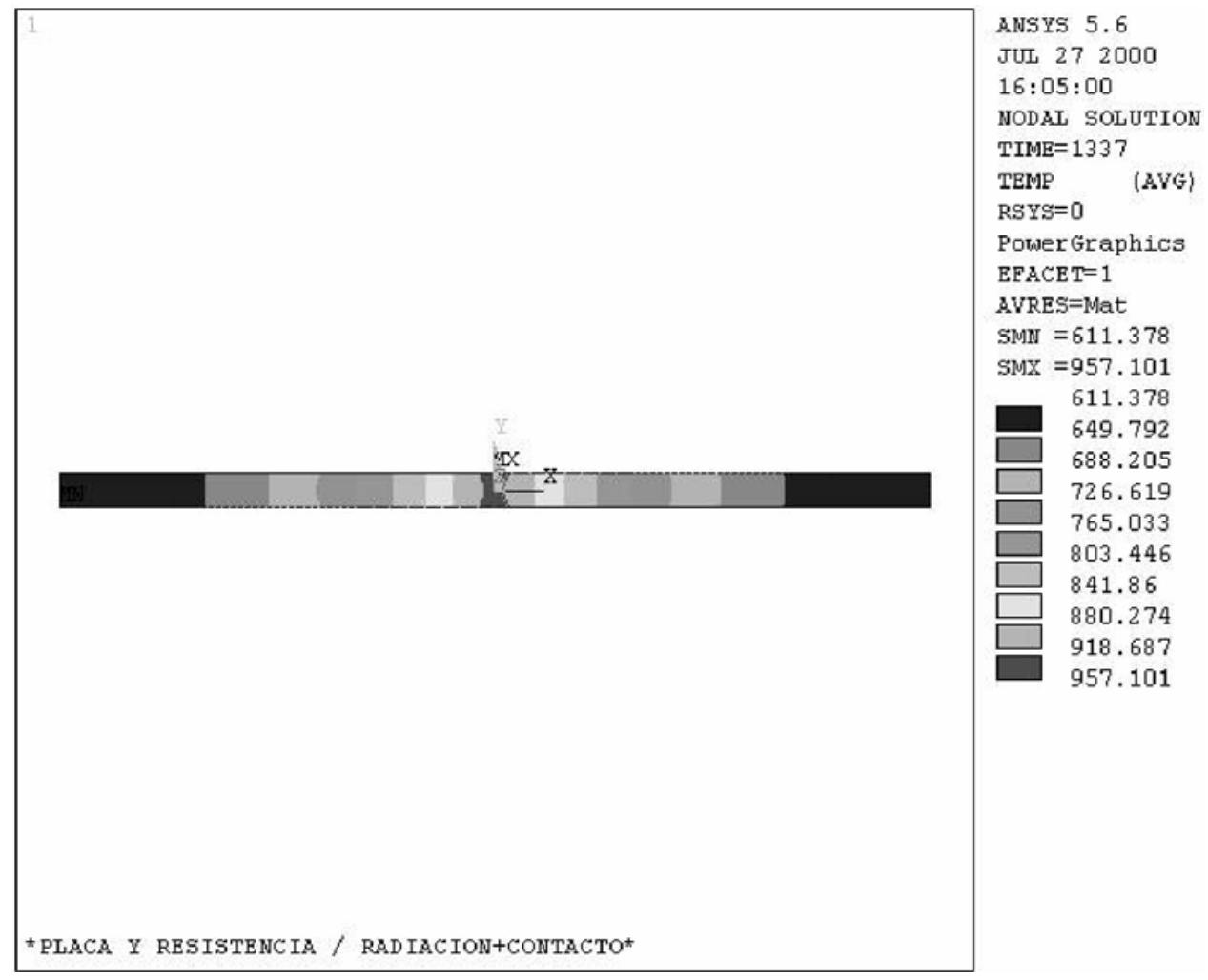

\subsection{Bending process at high temperature}

Once temperature distribution is obtained, the calculated temperature is assumed in corresponding elements in the mechanical model. Only the punch tip is modelled. No strain is assumed in the tools, considering rigid materials. The mesh in the mechanical model is refined in the central zone because of high strain and stress originating near the bend length, as is shown in Figure 8.

Material properties as a function of temperature were obtained from experimental tests, and introduced into the FEM code to simulate bending at high temperature.

Displacements in direction $\mathrm{x}$ are restricted in punch nodes and in sheet nodes located in plane yz. No displacement and no strain are allowed in the die. The sheet is bent due to displacement in direction y imposed in the punch. 
Figure 8 Mechanical model

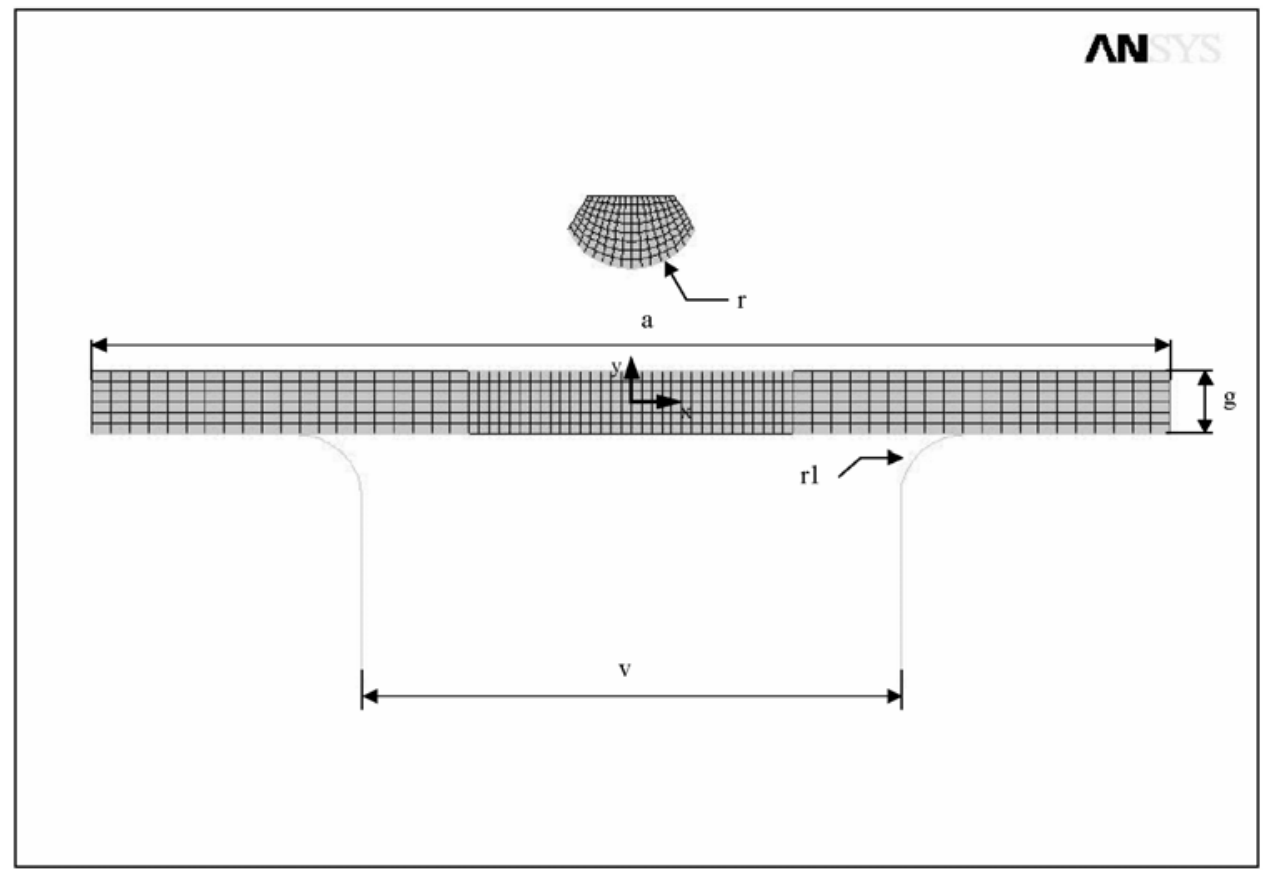

\subsection{Numerical results}

Firstly temperature was calculated with thermal model. Secondly temperature distribution was imposed in each node. Stress distribution was generated due to this non constant gradient of temperature, but these stresses were not significant when compared to those generated during punch displacement.

The punch was lowered to the desired position and finally the sheet was unloaded and springback occurred. Calculation time for the complete process was about two hours.

Results from this model are: bending force, angle before and after springback, strain and stress in the bent sheet.

Figure 9 shows resulting $\sigma_{x}$ (stress in direction $x$ ) in different punch displacements (bending angle $90^{\circ}$ ) and after unloading. From the output file, bending force, $\alpha_{0}$ and $\alpha_{f}$ (angle before and after unloading) were obtained.

Model validation was carried out comparing numerical and experimental results for bending force and bending angle. Errors were less than $5 \%$ in force and $4 \%$ in angle prediction.

Figure 10 shows as an example, bending force vs. punch displacement, at room temperature and at $750^{\circ} \mathrm{C}$, when sheet thickness was $4 \mathrm{~mm}$. Good agreement is observed between the numerical values and measured force. Bending force decreases significantly (more than $30 \%$ ) when temperature increases up to $750^{\circ} \mathrm{C}$. 
Figure 9 Sequence of $\sigma_{x}$ distribution
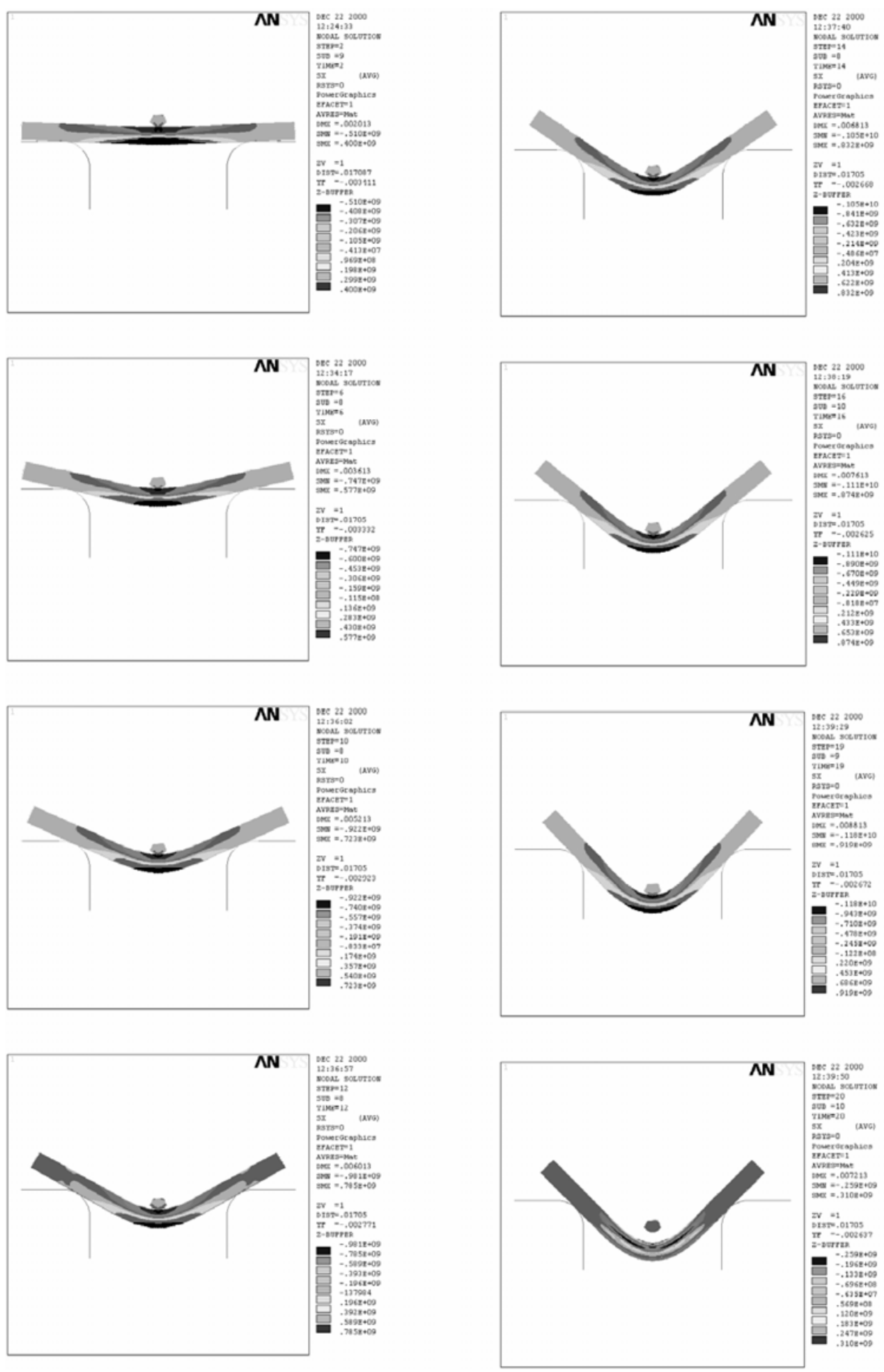
Figure 10 Numerical and experimental bending force at room temperature and $750^{\circ} \mathrm{C}$, sheet thickness $4 \mathrm{~mm}$

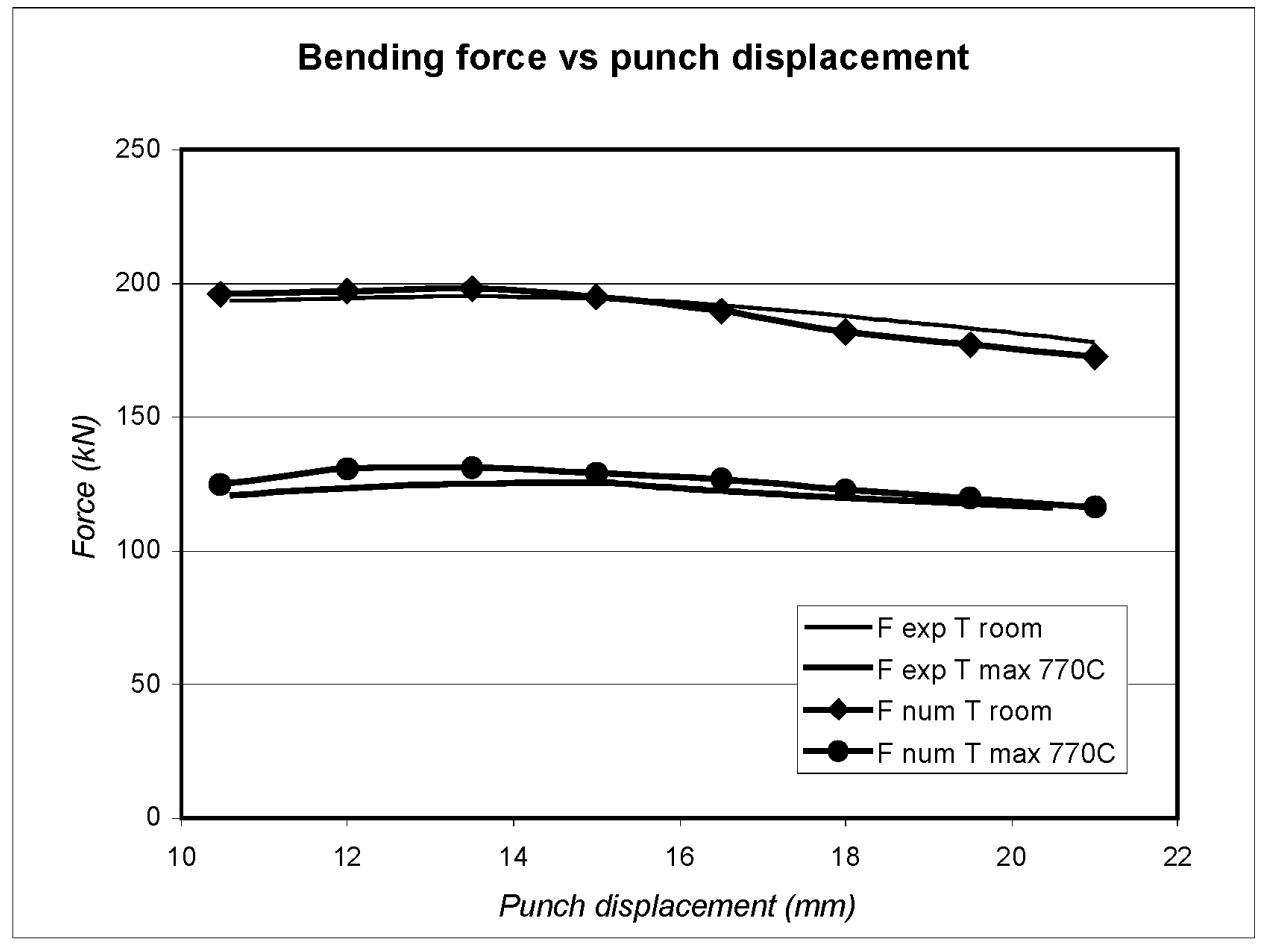

\section{Analytical thermo mechanical model}

Several authors have developed analytical models for air bending processes (de Vin, 2000; Streppel et al., 2001). Asnafi (2000) proposed a model with no assumptions about the shape of the sheet. Sheet curvature was related with moment in each section due to an estimated bending force. The model proposed in this paper is based in part, in Asnafi's work. Differences are introduced in the treatment of the bending force and in the thermal analysis of distribution of temperature in the sheet (Canteli et al., 2004). The thermomechanical model developed in this paper does not assume a known shape of the sheet. From equilibrium conditions, the relations between moment and curvature and constitutive equations, sheet curvature is calculated using an iterative process. Since the mechanical properties of material are dependent on sheet temperature, the temperature distribution should be previously established.

\subsection{Temperature distribution}

As is well known, material mechanical behaviour depends on temperature. When a metal sheet is locally heated along its bend length, a temperature distribution is generated in the sheet. This distribution depends on heating parameters, material properties and sheet geometry. 
Assuming the hypothesis deduced from numerical analysis, a thermal model is formulated as represented in Figure 11. Each element is $\Delta X$ wide and $1 \mathrm{~m}$ long, and $e$ thick. Uniform temperature $T_{n}$ in each element is assumed. Thermal flows in element $n$ are represented in Figure 12 being:

- conduction flows from element $n-1$ and to element $n+1\left(E_{\text {cond } n-1}, E_{\text {cond } n}\right)$

- convection flows from element $\mathrm{n}$ to air $\left(E_{\text {conv }}\right)$

- $\quad$ radiation flows from each resistance to element $n$ and from element $n$ to air ( $\left.E_{\text {radressheet, }}, E_{\text {rad }}\right)$.

In element $n=1$ conduction flows with resistances should also be considered.

In resistances, convection and radiation flows to air should be taken into account.

Figure 11 Scheme of thermal model

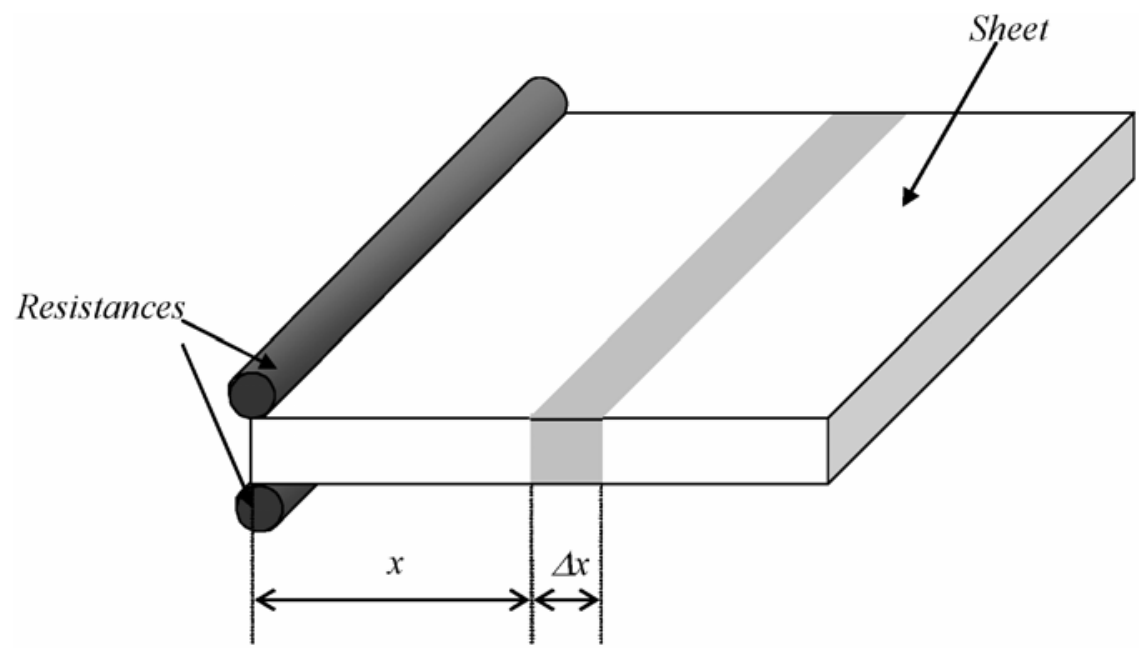

Figure 12 Thermal flows in analytical model

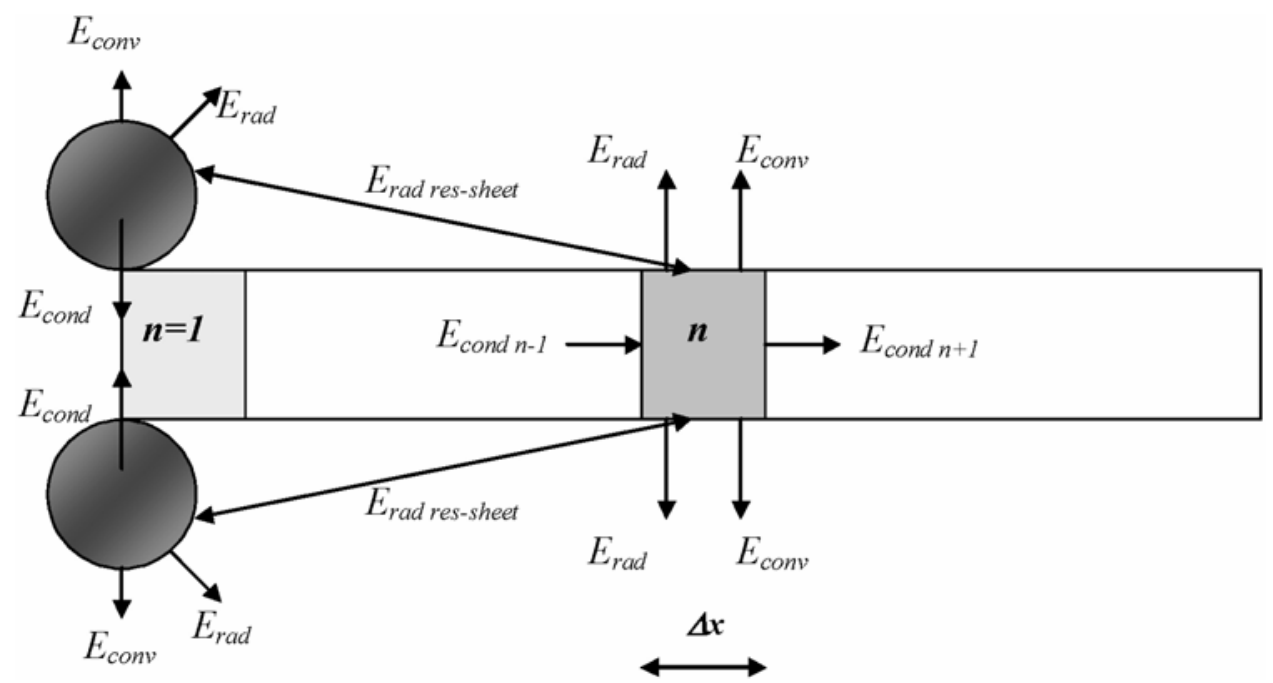




\section{Temperature in element $n$}

With this assumption, expression of temperature in element $n$, in time $t$ is given by equation

$$
T(t)_{n}=T(t-1)_{n}+\frac{\Delta E_{\text {cond }}-\Delta E_{\text {conv }}-\Delta E_{\text {rad }}+\Delta E_{\text {radres-sheet1 }}+\Delta E_{\text {radres-sheet } 2}}{C\left(T(t-1)_{n}\right) \rho_{\text {sheet }} \Delta x e} \Delta t .
$$

$\rho_{\text {sheet }}$ being material density, $C(T)$ specific heat (dependent on temperature), $\Delta E_{\text {cond }}$ energy increment (in each time unit) due to conduction flows, $\Delta E_{\text {conv }}$ energy decrement (in each time unit) in element $n$ due to convection flow to air, $\Delta E_{\text {rad }}$ energy decrement (in each time unit) in element $n$ due to radiation from element to air and $\Delta E_{\text {rad-sheet1,2 }}$ energy increment (in each time unit) in element $n$ due to radiation from resistances. Detailed equations for these thermal flows can be found in Canteli (2003) and Incropera and de Witt (1999).

\section{Resistances temperature}

Firstly, initial temperature in resistances $T_{\text {res }}$ (before contact with sheet) should be calculated as a function of heating parameters. The total power in resistances is dissipated by radiation and convection. The relation between radiation power $\left(W_{\text {rad }}\right)$ and convection power $\left(W_{\text {conv }}\right)$ and temperature in resistances is:

$$
W=W_{\text {rad }}+W_{\text {conv }}=2 \pi R\left\lfloor\sigma \varepsilon_{\text {res }}\left(T_{\text {res }}^{4}-T_{\text {room }}^{4}\right)-\bar{h}\left(T_{\text {res }}-T_{\text {room }}\right)\right\rfloor .
$$

The equation is solved using the iterative Newton method.

Resistances were put in contact with the first element, so contact thermal resistance between resistances and sheet should be established. During heating time the contact resistance varies because it depends on contact force and contact area and the last parameter depends on temperature. These parameters were established through experimental work (Canteli, 2003). Energy increment in the first element is:

$$
\Delta E_{\text {cond }}=\frac{1}{R} \frac{\delta}{2}\left(T_{\text {res }}-T_{0}\right) \text {. }
$$

$\delta$ being the contact area and $T_{0}$ the initial temperature in the first element.

Resistances temperature in time $t$ is calculated as:

$$
T(t)_{\text {res }}=T(t-1)_{\text {res }}+\frac{w-\Delta E_{\text {cond }}-\Delta E_{\text {conv }}-\Delta E_{\text {rad-air }}-\Delta E_{\text {rad-sheet }}}{C\left(T(t-1)_{\text {res }}\right) \rho_{\text {res }} \pi \frac{R^{2}}{2}} .
$$

$\Delta E_{\text {rad sheet }} \Delta E_{\text {rad air }}$ and $\Delta E_{\text {conv }}$ being the energy decrement in resistances because of radiation to sheet and air, and convection to air, respectively. Detailed equations for these thermal flows can be found in Canteli (2003) and Incropera and de Witt (1999).

Equations (1-4) are used to calculate temperature distribution in sheet and resistances at each time value. The time interval should be selected according to stability requirements. The stability criterion (Incropera and de Witt, 1999) in this case is,

$$
\Delta t \leq \frac{\Delta x^{2}}{2 \alpha}=\frac{(\Delta x)^{2} \rho c_{p}}{2 k} .
$$


Time values are fixed in order to obtain permanent temperature distributions. The choice of $\Delta x$ is based on a compromise between accuracy and computational requirements.

Once temperature distribution is obtained, it is possible to estimate the mechanical properties in each element. Parameters of the constitutive equation are a function of temperature, as was explained in the third section.

A comparison between measured and calculated temperatures showed that errors were always less than 2\% (Canteli et al., 2004).

\subsection{Bending process at high temperature}

The air bending model is schematically represented in Figure 13. An equivalent problem to the actual bending process, symmetrical with respect to the bending plane (YZ) is represented. The middle section of the sheet is attached and the force due to contact between die and sheet is applied at the contact point $\left(X_{k}, Y_{k}\right)$.

Figure 13 Scheme of mechanical model

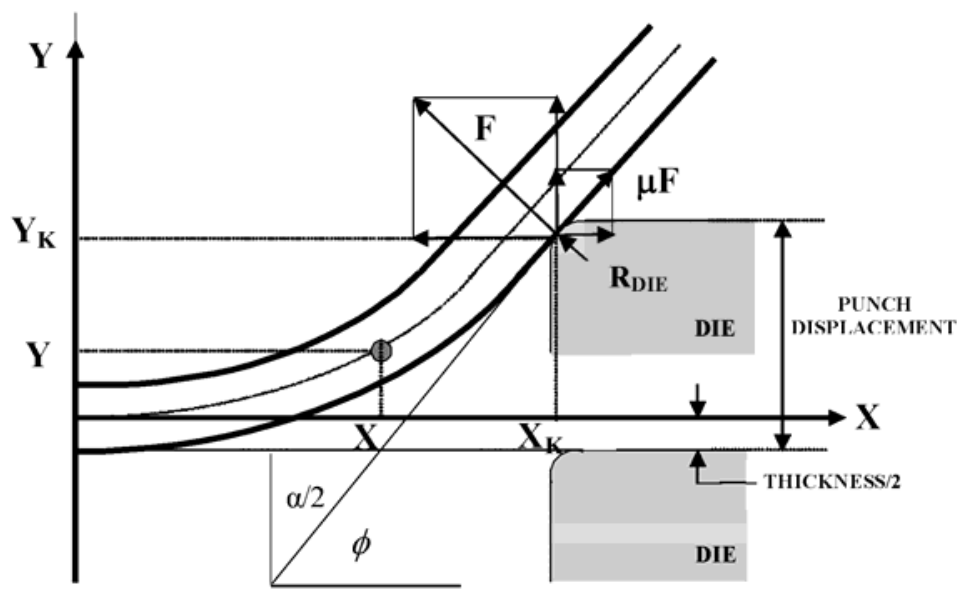

The sheet is discretised in elements $\Delta x$ wide, $1 \mathrm{~m}$ long, and $e$ thick, in the same way as it was done in the thermal model. Several hypotheses are assumed.

- $\quad$ During punch displacement, the reaction force between the die and the sheet $F$ varies, in module and direction, as the sheet is being bent. The point of application of this force in the sheet varies too.

- Effective die aperture (position of contact point) varies as the sheet is being bent.

- Friction between the sheet and the die is taken into account.

Moment in a generic element $n$ with central point coordinates $\left(X_{n}, Y_{n}\right)$ is given by:

$$
M_{n}=F\left\{(\sin \varphi-\mu \cos \varphi)\left(Y_{k}-Y_{n}\right)+(\cos \varphi+\mu \sin \varphi)\left(X_{k}-X_{n}\right)\right\}
$$

Where $\mu$ is the friction coefficient between the sheet and the die, $\left(X_{K}, Y_{K}\right)$ are the coordinates of sheet-die contact point, $F$ is the normal force due to this contact and $\varphi$ is the angle related to the bending angle $\alpha$ as $\varphi+\alpha / 2=\pi / 2$. 
This external moment should be in equilibrium with the internal moments. The internal moment for bending without tension is calculated with several assumptions (Marciniak and Duncan, 1992). In thin sheets, normal section planes may be considered to remain plane on bending and to converge on the centre of curvature as illustrated in Figure 14, representing a generic element $n$. Constant curvature is assumed in each element.

Figure 14 Element $n$ during bending

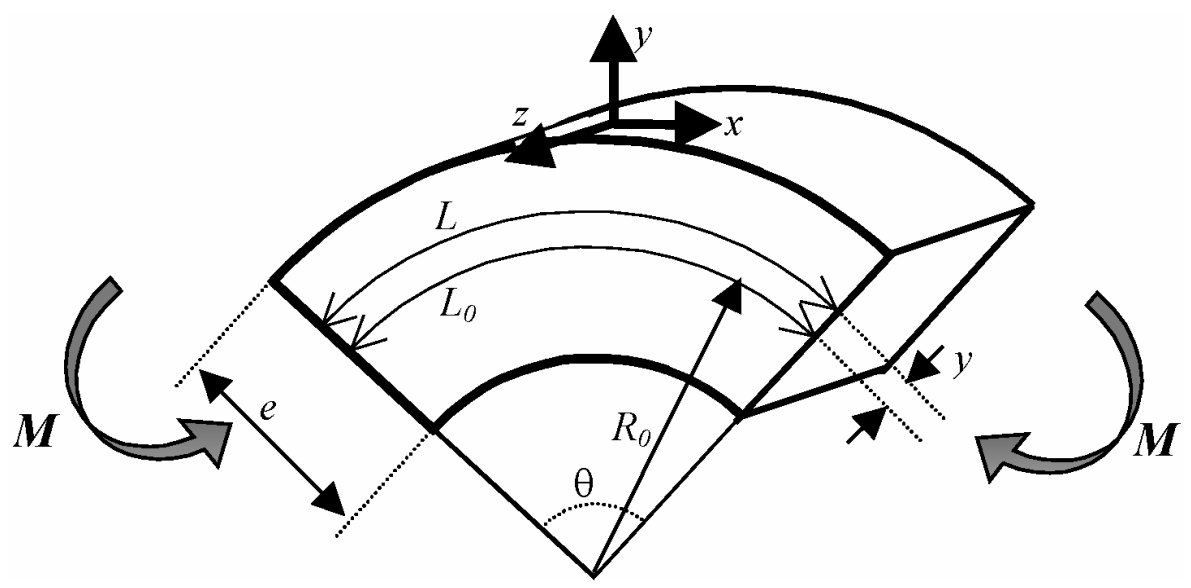

It is also considered that the principal directions of stress and strain coincide with the radial and circumferential directions, so that there is no shear in the radial plane, and the gradients of stress and strain are zero in the circumferential direction. The middle surface is not deformed. As the bend length is large compared with the thickness, plane strain conditions are assumed.

With these assumptions (see Figure 12) the engineering strain is calculated as

$$
e_{x}=\left(L-L_{0}\right) / L_{0}=y \theta / R_{0} \theta=y / R_{0} .
$$

Subscript 0 denotes magnitudes in the middle surface ( $R_{0}$ is radius in middle surface) and $x, y, z$ are local axes in element $n$. True strain $\varepsilon_{x}$ in direction $x$ is:

$$
\varepsilon_{x}=\ln \left(1+y / R_{0}\right) \cong y / R_{0} .
$$

From Levy-Mises equations (increasing monotonic load is considered) the effective strain and stress $\left(\varepsilon_{e}, \sigma_{e}\right)$ are calculated (Timoshenko, 2002):

$$
\begin{aligned}
& \varepsilon_{e}=2 \varepsilon_{x} / \sqrt{3} \\
& \sigma_{e}=\sigma_{x} \sqrt{3} / 2 .
\end{aligned}
$$

Moment equilibrium in element $n$ implies:

$$
M_{n}=\int_{-e / 2}^{+e / 2} \sigma_{x} y \mathrm{~d} y .
$$

In this equation $\sigma_{x}$ is related with $\sigma_{e}$ and so with $\varepsilon_{e}$, by the material constitutive equation. 
Validation of the model was carried out with stainless steel AISI 304. An elastoplastic model with lineal strain hardening was selected according to the previous mechanical characterisation of this material. Temperature dependence of the constitutive equation parameters was analysed in the previous section.

In the elastic region, the constitutive equation is:

$$
\sigma_{e}=E \varepsilon_{e} .
$$

And in the elastoplastic region

$$
\sigma_{e}=\sigma_{0 e}+K_{e} \varepsilon_{e} .
$$

Taking into account these considerations and equations, the equation for $\sigma_{x}$ in elastic region, can be written as:

$$
\sigma_{x}=\frac{E \varepsilon_{x}}{\left(1-v^{2}\right)}=\frac{E_{y}}{\left(1-v^{2}\right) R_{0}} .
$$

Where $v$ is the Poisson coefficient.

In the elastoplastic region, the equation for $\sigma_{x}$ is:

$$
(\sqrt{3} / 2) \sigma_{x}=\sigma_{0 e}+2 K_{e} \varepsilon_{x} / \sqrt{3} .
$$

And so:

$$
\sigma_{x}=\frac{2 \sigma_{0 e}}{\sqrt{3}}+\frac{4 K_{e} \varepsilon_{x}}{3}=\frac{2 \sigma_{0 e}}{\sqrt{3}}+\frac{4 K_{e} y}{3 R_{0}} .
$$

From equations (11), (14) and (16) the bending moment can be expressed as follows:

$$
M_{n}=2\left[\int_{0}^{\varepsilon_{x}^{*} R_{0}} \frac{E}{1-v^{2}} \frac{y^{2}}{R_{0 n}} \mathrm{~d} y+\int_{\varepsilon_{x}^{*} R_{0}}^{e / 2} \frac{2}{\sqrt{3}} \sigma_{0 e}+\frac{4 K_{e}}{3} \frac{y}{R_{0 n}} y \mathrm{~d} y\right]
$$

where integration limits in the equation are given by the point where yielding begins, corresponding to strain $\varepsilon_{x}^{*}$ given in equation (18):

$$
\varepsilon_{x}^{*}=\frac{\sigma_{0 e}\left(1-v^{2}\right)}{\left(E-K_{e}\right) \sqrt{1-v+v^{2}}} .
$$

Integration of equation (17) relates $M_{n}$ with curvature $R_{0 n}$ in element $n$ :

$$
M_{n}=\left(R_{0 n} \varepsilon_{x}^{*}\right)^{2}\left[\frac{2}{3} \varepsilon_{x}^{*}\left(\frac{E}{1-v^{2}}-\frac{4}{3} K_{e}\right)-\frac{2}{\sqrt{3}} \sigma_{0 e}\right]+0.2887 \sigma_{0 e} e^{2}+\frac{K_{e} e^{3}}{9 R_{0 n}} .
$$

As constitutive equation parameters $\left(E(T), \sigma_{0 e}(T), K_{e}(T)\right)$ depend on the temperature $T$, equation (19) should be formulated once temperature in each element is calculated, as was explained in the second section.

The moment calculated from equation (19) should be equal to the moment deduced from the external forces given in equation (6). 
Equation (20) relating curvature in each element and $Y(X)$ is given by Timoshenko (2002):

$$
\frac{1}{R_{0 n}}=\frac{\left(\frac{\mathrm{d}^{2} Y}{\mathrm{~d} X^{2}}\right)_{n}}{\left[1+\left(\frac{\mathrm{d} Y}{\mathrm{~d} X}\right)_{n}^{2}\right]^{\frac{3}{2}}} .
$$

The final curvature after unloading $1 / R_{f n}$ is calculated as:

$$
\frac{1}{R_{0 n}}-\frac{1}{R_{f n}}=\frac{M_{n}}{\frac{E e^{3}}{12\left(1-v^{2}\right)}} .
$$

And the final $Y(X)$ of the sheet (in each element $n$ ) after unloading, is related to the final curvature as follows:

$$
\frac{1}{R_{f n}}=\frac{\left(\frac{\mathrm{d}^{2} Y}{\mathrm{~d} X^{2}}\right)_{n}}{\left[1+\left(\frac{\mathrm{d} Y}{\mathrm{~d} X}\right)_{n}^{2}\right]^{\frac{3}{2}}} .
$$

\subsection{Analytical results}

In a first step $R_{0}^{*}$, radius where yielding occurs in $y= \pm e / 2$, is calculated as follows:

$$
R_{0}^{*}=\frac{e \sqrt{3}}{4 \sigma_{0 e}}\left(\frac{E}{1-v^{2}}-\frac{4}{3} K_{e}\right) .
$$

As has been shown, the moment resulting from external forces is calculated (equation 6). Note that since $F, \varphi, X_{k}, Y_{k}$ are not known, these parameters should be arbitrarily fixed, as a first step of the iterative process.

This moment in element $n$, should be equal to the internal moment resulting from the equation (19). The Newton method (Bilal and McCuen, 1996) is used to calculate $R_{0 n}$ from this equation. If $R_{0 n}<R_{0}^{*}$, (elastoplastic) then $R_{0 n+1}$ is calculated in a similar way. If $R_{0 n} \geq R_{0}^{*}$ (elastic) then $R_{0 n}$ is recalculated as

$$
R_{0 n}=\frac{E}{1-v^{2}} \cdot \frac{1}{M_{n}} \cdot \frac{e^{3}}{12}
$$

This calculation process relates external forces with moments at each element and moments with curvature. The principal disadvantage of the process derives from the fact that the moment at each point is a function of its own coordinates, the contact point coordinates and contact angle at this point. However, these parameters are not known. When a force is applied, the resulting sheet displacement is not known, 
and so, function $Y(X)$, contact point coordinates and contact force direction are not known.

From equation (21), $Y(X)$ and its derivatives are obtained. Boundary conditions are $Y=0$ and $(\mathrm{d} Y / \mathrm{d} X)=0$ in $X=0$, and the solving method is 4th order Runge-Kutta (Hultquist, 1988).

Then, bending angle before springback is calculated. When unloading occurs, the final curvature in each point after springback is calculated as:

$$
\frac{1}{R_{f n}}=\frac{1}{R_{0 n}}-\frac{12\left(1-v^{2}\right) M_{n}}{E e^{3}} .
$$

And the relation between curvature and final $Y(X)$ is given by equation (22). This equation is also solved by a 4th order Runge-Kutta method with contour conditions $Y=0$ and $\mathrm{d} Y / \mathrm{d} X=0$ in $X=0$. The bending angle after springback is calculated. Differences between the estimated and calculated values indicate if it is necessary to iterate again. The procedure is stopped once a convergence criterion is reached.

The mechanical model predicts punch displacement and bending force once the bending angle is fixed. Other interesting parameters like stress and strain distribution can be obtained from the model.

In validation tests, the calculated punch displacement was imposed in the press brake and bending force, and the final angle before and after unloading were measured. Validation is based on comparison between measured and calculated values.

In calculated the bending force, the maximum errors were less than $5 \%$, both at room and elevated temperatures. Error in springback angle was inferior to $1.5 \%$, at room and at high temperature.

Figure 15 shows the calculated and measured bending forces at room temperature, $580^{\circ} \mathrm{C}$ and $750^{\circ} \mathrm{C}$, the sheet thickness being $6 \mathrm{~mm}$ in these cases. Good correlation between analytical and experimental results is observed. Similar results were obtained in other tests, carried out in sheets with thickness ranging from $1 \mathrm{~mm}$ to $6 \mathrm{~mm}$.

\section{Software for industrial implementation}

Software based on the analytical thermo mechanical model was developed using Visual Basic. Previous validation of the analytical model showed good accuracy when compared with experimental results.

Analytical models described in the previous section require advanced knowledge of metal forming processes and mathematical tools. Easy implementation of these models at all levels of manufacturing industry implies the development of computer tools that facilitate the calculation process. 
Figure 15 Analytical and experimental bending force vs. punch displacement at room temperature, $580^{\circ} \mathrm{C}$ and $750^{\circ} \mathrm{C}$

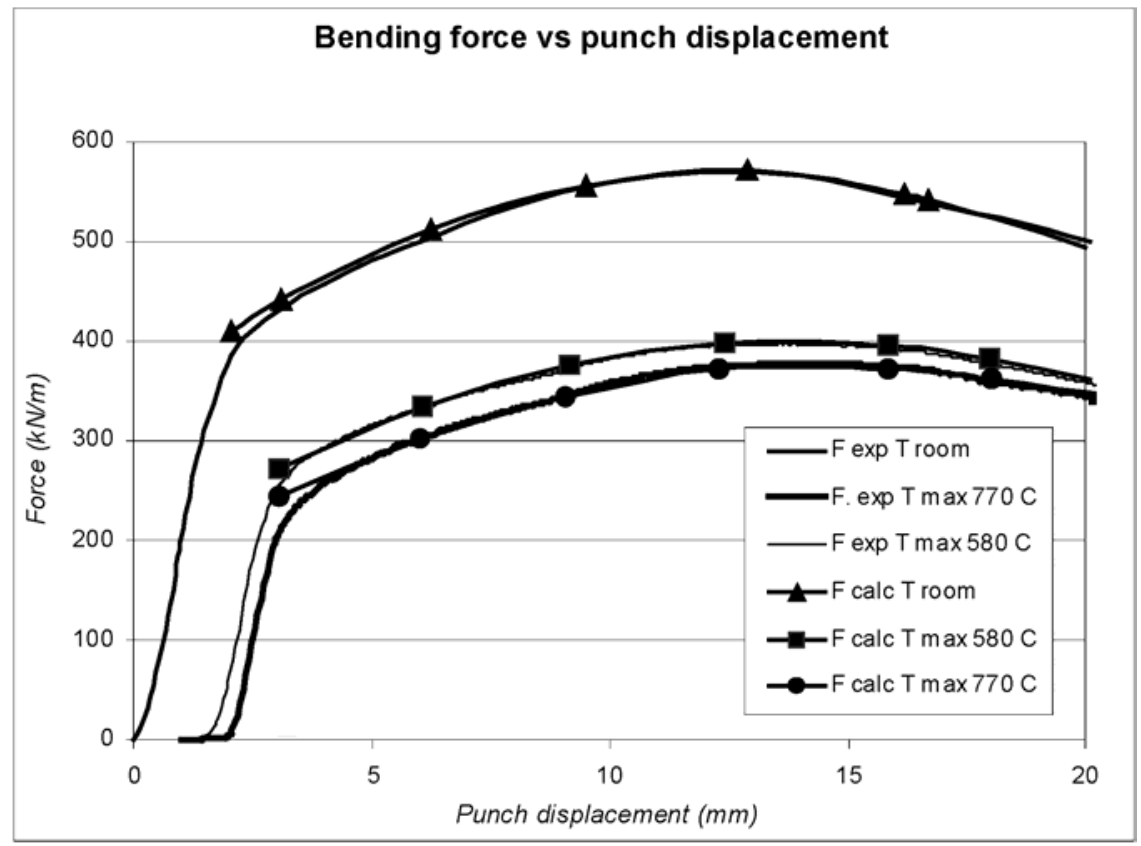

The thermo mechanical model was converted into a software with two blocks: thermal, based on the formulation described in Section 5.1 and mechanical, based on the formulation described in Section 5.2. The thermal block calculates temperature distribution once heating parameters, material characteristics and sheet geometry are established. The mechanical block imports temperature distribution from the thermal programme and calculates the main bending parameters once the desired final bending angle is fixed. Such a tool combines time and cost reduction during design and manufacture of sheet component. No special knowledge is required to use the software. It is friendly to use, based on the wellknown system of Windows. Input parameters related to technical characteristics of the experimental device are easy to obtain. The software includes a materials library with properties of usual sheet metals. Figures 16 and 17 show the thermal and mechanical windows of the programme respectively. The CPU time of the developed software depends on mesh width. Values of this parameter around $1 \mathrm{~mm}$ give good accuracy with a CPU time of only a few seconds (in a PC Pentium V, 2.4 MHz). As the solution of the FEM model takes more than two hours, the advantage of the use of the developed tool is clear.

A flowchart of the air bending process, at room temperature and at high temperatures is shown in Figure 18. The bending process at room temperature is carried out successfully in industry with conventional materials. Most of NC press brake is able to predict accurately, process parameters in air bending to obtain the final geometry. Several trial work pieces should be produced before the final parameter adjustment. 
Figure 16 Computer tool for thermal calculations

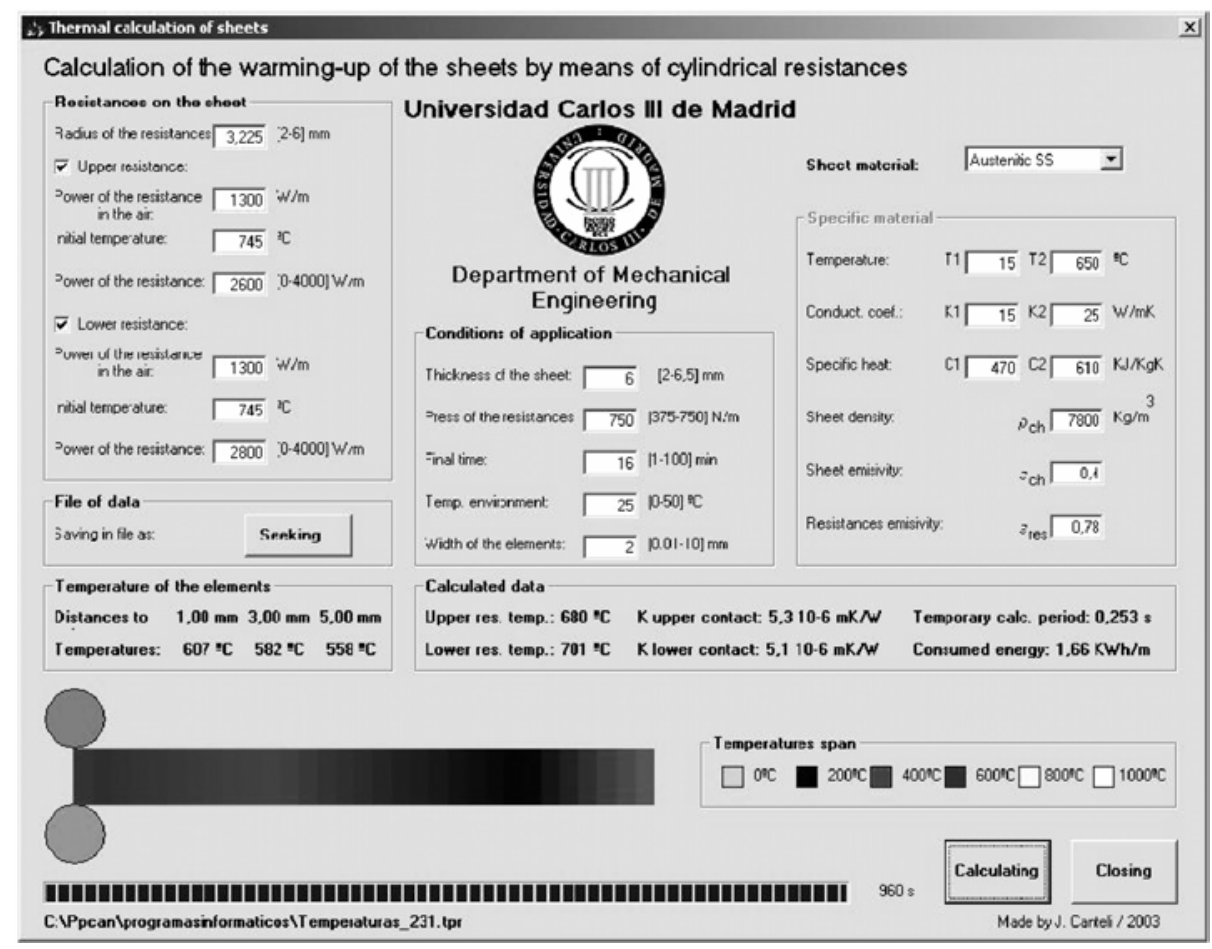

Figure 17 Computer tool for mechanical calculations

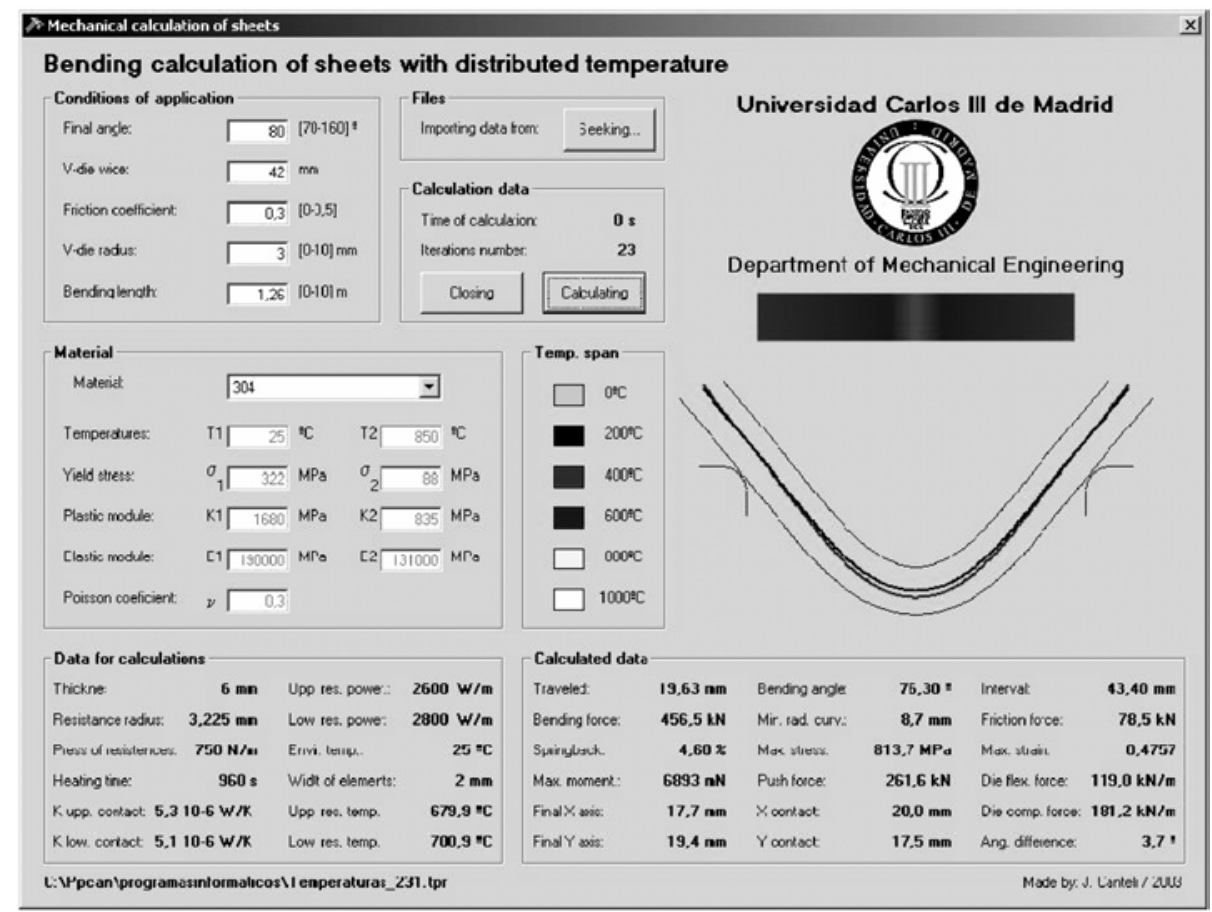


Figure 18 Flowchart of bending process at room temperature and high temperature

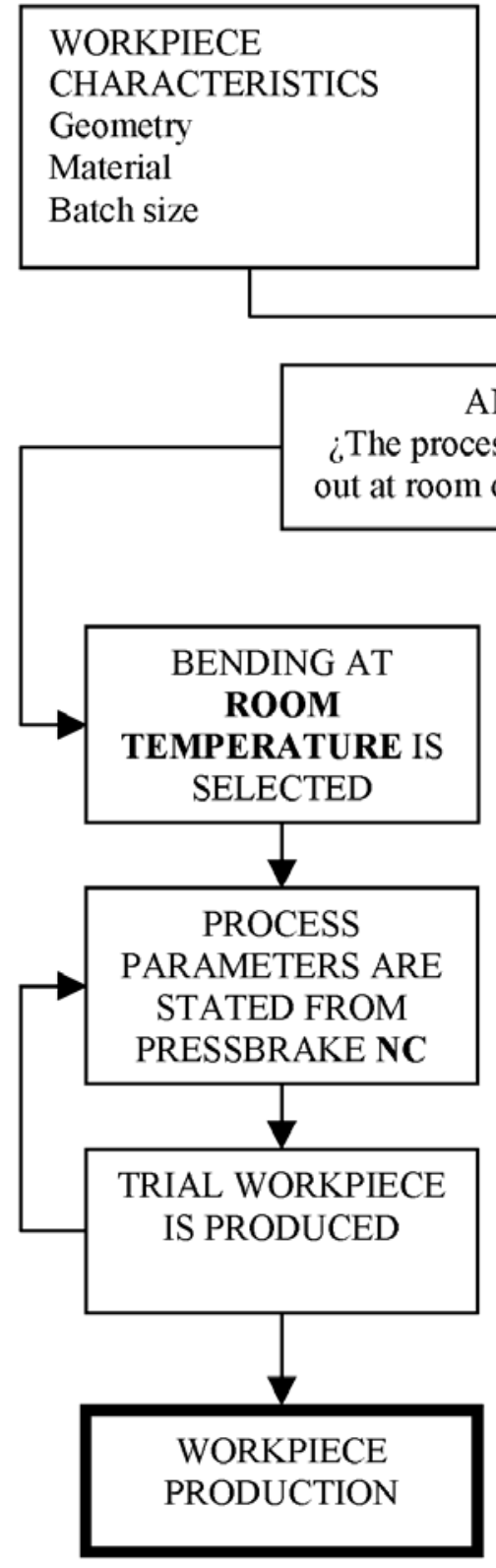

PRESSBRAKE PARAMETERS

Load range

Controllers (NC)

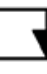

\section{ANALYSIS}

¿The process should be carried out at room or high temperature?

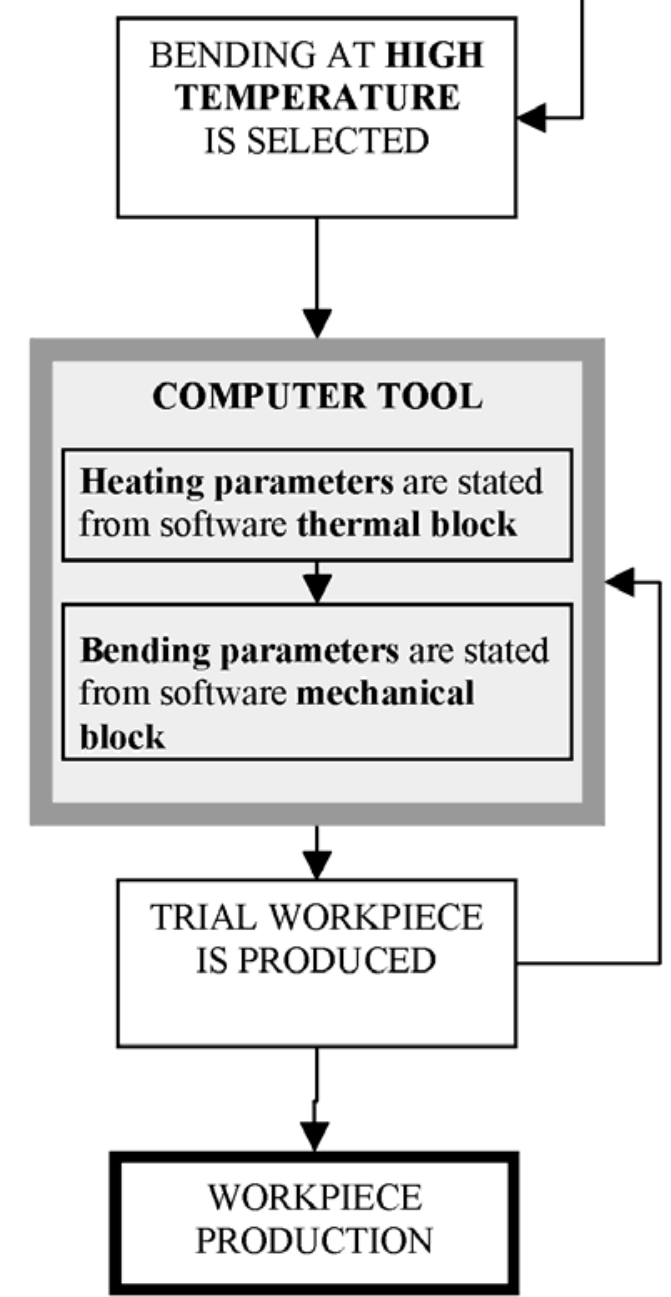


If new materials are involved, high strength steel for example, or big thickness is needed in the work piece, it may be necessary to bend at high temperature, because formability of the work piece material is improved and the bending force decreases.

Temperature affects material behaviour; so the predictions of the NC machine are not valid in this case. The software could be used to predict bending parameters.

\section{Conclusions}

In this paper, a new computer tool for simulation of bending processes at high temperature is presented. This software allows calculating temperature distribution in the sheet, bending force and springback, once the process parameters are defined. Calculations are based on the analytical thermo mechanical model previously developed and validated. The CPU time was only few seconds; a clear advantage compared with that involved in a FEM analysis of bending at high temperature, carried out in a FEM code.

As the software is based on analytical models that showed good accuracy when calculated and experimental results are compared, and it results in time saving, it seems to be an interesting tool for designers and manufacturers.

The work is focused on air bending at high temperature, as an example of improved technique of sheet metal forming, specially indicated for high strength materials.

Experimental work demonstrated that air bending at high temperature is possible and relatively easy to implement in industry. Temperature measurements in thermal tests showed that both numerical and analytical thermal models are able to predict (errors less than 2\%) temperature distribution accurately, once heating parameters are fixed. Bending tests allowed measurement of bending force vs. punch displacement and springback angle, at room and high temperatures. Calculated errors (less than 5\% in predicted bending force and less than $1.5 \%$ in predicted springback angle) showed good accuracy of the numerical and analytical bending models both at room and elevated temperatures. As expected, high temperature along bend length results in reduced bending force and springback.

The work presented in this paper could help to improve bending processes in industry. Firstly, flexibility in processes required because of small batch sizes and short lead times in sheet metal part manufacturing, could be achieved using accurate models to predict process parameters as they are inexpensive and fast tools. On the other hand, forming at elevated temperature could increase the range of use of machine and tools. Also, metal sheet manufacture at high temperature could improve processes when improved mechanical properties of the material work piece are involved, as in the case of high strength steels, recently implemented in automobile industry.

Future work in this research line should be focused on other sheet metal techniques, improving technologies and developing accurate models with the aim of achieving cost and time saving, two objectives common to all manufacturers. 


\section{References}

Anokye-Siribor, K. and Singh, U.P. (2000) 'A new analytical model for pressbrake forming using in-process identification of material characteristics', J. Mater. Process. Technol., Vol. 99, pp.103-112.

Asnafi, N. (2000) 'Springback and fracture in v-die air bending of thick stainless steel sheets', Materials and Design, Vol. 21, pp.217-236.

Bilal, M.A. and McCuen, R.H. (1996) Numerical Methods for Engineers, Prentice-Hall International, London (UK).

Bouchard, A. and Aoussat, A. (2003) 'Design process perceived as an information process to enhance the introduction of new tools', Int. J. Vehicle Design, Vol. 31, No. 2, pp.162-175.

Bouchard, A. and Aoussat, A. (2003) 'Modellization of the car design process', Int. J. Vehicle Design, Vol. 31, No. 1, pp.1-10.

Bouvier, S., Alves, J.L., Oliveira, M.C. and Menezes, L.F. (2005) 'Modelling of anisotropic work-hardening behaviour of metallic materials subjected to strain-path changes', Comp. Mat. Science, Vol. 32, pp.301-315.

Cai, Z-Y. and Li, M-Z. (2005) 'Finite element simulation of multi-point sheet forming process based on implicit scheme', J. Mat. Process. Technol., Vol. 161, pp.449-455.

Canteli, J.A. (2003) Air Bending Process of Stainless Steel with Local Heating, PhD Thesis, University Carlos III of Madrid.

Canteli, J.A., Cantero, J.L. and Miguélez, M.H. (2004) 'Experimental validation of thermomechanical modelling of air bending’, J. Mater. Process. Technology, submitted 2004.

Canteli, J.A., Cantero, J.L. and Miguélez, M.H. (2004) 'Theoretical analysis of air bending at high temperature', J. Mater. Process. Technology, submitted 2004.

Chan, W.M., Chew, H.I., Lee, H.P. and Cheok, B.T. (2004) 'Finite element analysis of spring-back of V-bending sheet metal forming processes’, J. Mat. Processing Technology, Vol. 148, pp.15-24.

Chien, W.Y., Pan, J. and Tang, S.C. (2004) A combined necking and shear localization analysis for aluminum sheets under biaxial stretching conditions', Int. J. Plasticity, Vol. 20, pp.1953-1981.

de Vin, L.J. (2000) 'Curvature prediction in air bending of metal sheet', J. Mater. Process. Technol., Vol. 100, pp.257-261.

de Vin, L.J., Streppel, A.H., Singh, U.P. and Kals, H.J.J. (1996) 'A process model for air bending', J. Mater. Process. Technol., Vol. 57, pp.48-54.

Elkins, K.L. and Sturges, R.H. (1999) 'Springback analysis and control in small radius air bending', J. Manufacturing Science and Engineering, Vol. 121, pp.679-688.

Forcellese, A., Fratini, L., Gabrielli, F. and Micari, F. (1998) 'The evaluation of springback in 3D stamping and coining processes’, J. Mat. Processing Technology, Vols. 80-81, pp.108-112.

Gibbs, G.B. (1969) 'Thermodynamic analysis of dislocation glide controlled by dispersed local obstacles', Mater. Sci. Engng., Vol. 4, p.313-318.

Gomes, C., Onipede1, O. and Lovell, M. (2005) 'Investigation of springback in high strength anisotropic steels’, J. Mat. Processing Technology, Vol. 159, pp.91-98.

Guo, Y.Q., Li, Y.M., Bogard, F. and Debray, K. (2004) 'An efficient pseudo-inverse approach for damage modeling in the sheet forming process', J. Mat. Processing Technology, Vol. 151, pp.88-97.

Hsu, C.W., Ulsoy, A.G. and Demeri, M.Y. (2002) 'Development of process control in sheet metal forming', J. Mater. Process. Technol., Vol. 127, pp.361-368.

Hultquist, P.F. (1988) Numerical Methods for Engineers and Computer Scientists, Menlo Park, Benjamin-Cummings.

Incropera, F.P. and de Witt, D.P. (1999) Fundamentals of Heat and Mass Transfer, Addison Wesley Longman, New York, pp.827-837. 
Iwamoto, T. and Tsuta, T. (2000) 'Computational simulation of the dependence of the austenitic grain size on the deformation behaviour of TRIP steels', Int. J. Plasticity, Vol. 16, pp.791-804.

Jansson, T., Andersson, A. and Nilsson, L. (2005) 'Optimization of draw-in for an automotive sheet metal part. An evaluation using surrogate models and response surfaces’, J. Mat. Processing Technology, Vol. 159, pp.426-434.

Kima, J., Sona, B.M., Kanga, B.S., Hwang, S.M. and Park, H.J. (2004) 'Comparison stamping and hydro-mechanical forming process for an automobile fuel tank using finite element method', J. Mat. Process. Technol., Vols. 153-154, pp.550-557.

Klepaczko, J.R. (1975) 'Thermally activated flow and strain rate history effects for some polycristalline FCC metals’, Mat. Sci. and Engineering, Vol. 18, pp.121-135.

Kocks, U.F. (1976) 'Laws for work-hardening and low-temperature creep', J. Eng. Mat. Tech., Vol. 98, pp.76-85.

Kopac, J. and Kampus, Z. (2005) 'Incremental sheet metal forming on CNC milling machine-tool', J. Mat. Process. Technol., Vol. 162-163, pp.622-628.

Lademo, O.G., Hopperstad, O.S., Berstad, T. and Langseth, M. (2004) 'Prediction of plastic instability in extruded aluminium alloys using shell analysis and a coupled model of elasto-plasticity and damage', J. Mat. Processing Technology, Vol. 166, No. 2, pp.247-255.

Lang, L.H., Wang, Z.R., Kang, D.C., Yuang, S.J., Zhang, S.H., Danckert, J. and Nielsen, K.B. (2004) 'Hydroforming highlights: sheet hydroforming and tube hydroforming', J. Mat. Processing Technology, Vol. 151, pp.165-177.

Lei, L.P., Hwang, S.M. and Kang, B.S. (2001) 'Finite element analysis and design in stainless steel sheet forming and its experimental comparison', J. Mat. Processing Technology, Vol. 110, pp.70-77.

Li, X., Yang, Y., Wang, Y., Bao, J. and Li, S. (2002) 'Effect of the material-hardening mode on the springback simulation accuracy of V-free bending', J. Mat. Processing Technology, Vol. 123, pp.209-211.

Liu, Y., Peng, X., Qin, Y., (2004) 'FE simulation for concurrent design and manufacture of automotive sheet-metal parts', J. Mat. Process. Technol., Vol. 150, pp.145-150.

Marciniak, Z. and Duncan, J. (1992) 'Mechanics of sheet metal forming', Edward Arnold, London (UK), pp.69-98.

Meyers, M.A., Benson, D.J., Vohringer, O., Kad, B.K., Xue, Q. and Fu, H. (2002) 'Constitutive description of dynamic deformation: physically-based mechanisms', Mat. Sci. and Engineering, Vol. A322, pp.194-216.

Nishino, S., Ohya, K. and Naruishi, K. (2003) 'Proposal for reducing press working load and highly accurate evaluation of springback error in bending automobile sheet metal', JSAE Review, Vol. 24, pp.283-288.

Novotny, S. and Geiger, M. (2003) 'Process design for hydroforming of lightweight metal sheets at elevated temperatures’, J. Mat. Processing Technology, Vol. 138, pp.594-599.

Rusinek, A., Zaera, R. and Klepaczko, J.R. (2005) 'Material characterization of a mild steel and constitutive relation for a wide range of strain rates and temperatures for 3D numerical simulations', Int. J. Mech. Sci., pp.1-38, submitted 2005.

Serri, J., Martiny, M. and Ferron, G. (2005) 'A numerical analysis of the formability of unstable austenitic steels’, J. Mat. Processing Technology, Vol. 164-165, pp.1241-1247.

Streppel, A.H., Lutters, D., Ten Brinke, E., Pijlman, H.H. and Kals, H.J.J. (2001) 'Process for modelling for air bending: validation by experiments and simulations', J. Materials Processing Technology, Vol. 115, pp.76-82.

Sutherland, J., Gunter, K., Allen, D., Bauer, D., Bras, B., Gutowski, T., Murphy, C., Piwonka, T., Sheng, P., Thurston, D. and Wolf, E. (2004) 'A global perspective on the environmental challenges facing the automotive industry: state-of-the-art and directions for the future', Int. J. Vehicle Design, Vol. 35, Nos. 1-2, pp.86-110. 
Timoshenko (2002) Resistencia de Materiales, Thomson, Madrid.

Vin, L.J. (2001) 'Expecting the unexpected, a must for accurate brakeforming', J. Materials Processing Technology, Vol. 117, pp.244-248.

Walczyk, D.F., Lakshmikanthan, J. and Kirk, D.R. (1998) 'Development of a reconfigurable tool for forming aircraft body panels’, J. Manufacturing Systems, Vol. 17, No. 4, pp.287-296.

Woznica, K. and Klepaczko, J.R. (2003) 'Modelling of inelastic bending of a metal sheet with thermal coupling', Int. J. Mechanical Sciences, Vol. 45, pp.359-372.

Xua, W.J., Fang, J.C., Wang, X.Y., Wang, T., Liu, F. and Zhao, Z.Y. (2005) 'A numerical simulation of temperature field in plasma-arc forming of sheet metal', J. Mat. Process. Technol., Vol. 164-165, pp.1644-1649. 